Portland State University

PDXScholar

$1-2019$

\title{
Heard on the Net: "Academic" and "Freedom" Are Two Words for Nothing Left to Lose
}

\author{
Jill Emery \\ Portland State University, jemery@pdx.edu \\ Amy Buckland \\ University of Guelph \\ Ashley Farley \\ Bill and Melinda Gates Foundation
}

Follow this and additional works at: https://pdxscholar.library.pdx.edu/ulib_fac

Part of the Scholarly Communication Commons, and the Scholarly Publishing Commons Let us know how access to this document benefits you.

\section{Citation Details}

Jill Emery, Amy Buckland and Ashley Farley. (2019). "Heard on the Net: "Academic" and "Freedom" Are Two Words for Nothing Left to Lose" The Charleston Advisor Vol. 20 Iss. 3, p. 62 - 63.

This Article is brought to you for free and open access. It has been accepted for inclusion in Library Faculty Publications and Presentations by an authorized administrator of PDXScholar. Please contact us if we can make this document more accessible: pdxscholar@pdx.edu. 


\section{"Academic" and "Freedom" Are Two Words for Nothing Left to Lose}

doi:10.5260/chara.20.3.62

By Jill Emery (Collection Development \& Management Librarian, Portland State University)

$<$ jemery@pdx.edu>

With contributions from:

Amy Buckland (Head-Research \& Scholarship, University of Guelph)

<buckland@uoguelph.ca>

Ashley Farley (Associate Officer-Knowledge E Research Services,

The Bill and Melinda Gates Foundation)

<Ashley.Farley@gatesfoundation.org>

I September 2018, The European Commission released a statement called Plan S and cOAlition S which calls for more immediate access to research findings from their European members. ${ }^{1}$ This statement builds upon and asserts more readily the proposition put forward by the European Union two years prior (2016) that had come to be known as EU Horizon 2020. The significant difference with Plan S is that there are funding bodies willing to accept and put into action the goals of this statement quickly. Specifically, these agencies are Wellcome Trust and the Bill and Melinda Gates Foundation. Wellcome Trust outlined changes to their new open access policy and released these shortly after the Plan S statement was made. ${ }^{2}$ The Bill and Melinda Gates Foundation also announced they will be updating their Open Access policy over the next 12 months. ${ }^{3}$ In November 2018, a set of guidelines spelling out how cOAlition S can fulfill the main principles of immediate access to research findings. In essence, the guidelines state:

By 2020 scientific publications that result from research funded by public grants provided by participating national and European research councils and funding bodies, must be published in compliant Open Access Journals or on compliant Open Access Platforms. ${ }^{4}$

In the United States, there has be a mix of reactions which range from being in full support to those being in strong opposition via blogs and social media platforms. There is much to be worked out regarding the implementation of these changes but with the funding bodies in support, these statements appear to carry more weight. In addition, the main difference with these announcements and the reactions to them is that there is suddenly a much greater awareness and interest in this topic at much higher administrative levels within the academy. This is also due in part to the strong messages coming from two important funding bodies. The good news is that many librarians are ready for these conversations and have a wealth of information to pull on as institutions begin to explore and understand what local impacts may be.

On top of these discussions, comes the news from the California Digital Library that they are attempting to flip the subscription model of their Elsevier big deal into a Publish and Read model. ${ }^{5}$ In a "publish and read" subscription model, access to content is still made available to the subscribing libraries, but likely no longer in perpetuity or with post cancellation rights, and perhaps even in a more limited way than under the previous subscription deal and all faculty at the participating institutions are able to publish content $\mathrm{OA}$ in the majority of the previously subscribed titles with no APCs (Article Processing Charges). As noted in their press release, University of California au- thors produce around $10 \%$ of the total content published by Elsevier in their journals. This could potentially be a significant shift, if University of California faculty choose to publish in other scholarly publications due to this deal not succeeding.

One of the more intriguing arguments that is being raised is whether funders or universities stating how and where research is published impacts the academic freedom of the faculty members producing the scholarship. The American Association of University Professors put forward the tenets of academ ic freedom in the "1940 Statement of Principles on Academic Freedom and Tenure." The document outlines what is traditionally defined as "academic freedom." Under the heading of Academic Freedom, this is the statement made:

Teachers are entitled to full freedom in research and in the publication of the results, subject to the adequate performance of their other academic duties; but research for pecuniary return should be based upon an understanding with the authorities of the institution. ${ }^{6}$

This statement does not appear to weigh in on where and how publication occurs other than to indicate, specific arrangements may need to be made when you're making a profit off your publishing. In December 2010, Inside Higher Education published an article entitled: "Defining Academic Freedom" and in this work notes the following as being covered:

Academic freedom gives both students and faculty the right to study and do research on the topics they choose and to draw what conclusions they find consistent with their research, though it does not prevent others from judging whether their work is valuable and their conclusions sound. To protect academic freedom, universities should oppose efforts by corporate or government sponsors to block dissemination of any research findings.

Academic freedom protects faculty members and students from reprisals for disagreeing with administrative policies or proposals. $^{7}$

Again, neither statement appears to provide any indication that an OA mandate or funder requirement to publish OA is impeding anyone's academic freedom. Faculty members can readily disagree with these policies but cannot ignore them if they are put in place. At best, the argument of academic freedom in light of Plan S or in the decisions made a given institution around scholarship dissemination is tenuous at best.

For this column, I solicited feedback from two colleagues to provide their take on this argument and here are their replies. 


\section{AMY BUCKLAND, HEAD-RESEARCH \& SCHOLARSHIP, UNIVERSITY OF GUELPH}

"I do not believe faculty actually are concerned that open access requirements are infringing their academic freedom. I believe that faculty are under-resourced (in a variety of ways) in order to meet new funding agency requirements, and the academic freedom argument has traction on many campuses as one of the few ways to get the attention of administration. Since there are multiple mechanisms to make research openly available (the requirement), in almost every case researchers can publish anywhere they choose (the academic freedom concern), so this argument has no real foundation. Libraries are doing what they can to support researchers with these new requirements, and as most institutions in Canada are publicly-funded, the responsibility to make publicly-funded research available for everyone to read is a very real driver in how we resource scholarly communication and research data management teams. We need to do more to ensure that the mechanisms to make work openly available are as easy as possible for the researcher. Ultimately, academic freedom does not grant researchers the right to hide their research. Or put another way, the right of academic freedom does not trump the right of the public to read publicly-funded research. Let's position this discussion where it ought to be, how can we build the infrastructure, both within the university and within academia as a whole, to better support researchers to make their work open?"

\section{ASHLEY FARLEY, ASSOCIATE OFFICER-KNOWLEDGE \& RESEARCH SERVICES, THE BILL AND MELINDA GATES FOUNDATION}

"I do not consider myself to have in-depth expertise on the subject of academic freedom; however I have worked in and around academia long enough to see the incongruences of the concept, especially in its use to argue against Plan S. I firmly believe that the essence of academic freedom should not be deployed to impede progress made towards a more open and inclusive scholarly communications ecosystem. It's important to keep in mind that a global definition of academic freedom does not yet exist and that each definition exists on a spectrum - from loosely to strictly defined. In the United States, where I live and work, the concept of academic freedom is similar to the First Amendment - protecting one's speech from any retribution from the government. In regards to academia this means having the ability to explore research topics without fear of government interference in the form of censorship or retaliation. It's not meant for academics to act freely without responsibilities, requirements or oversight. As academics are often tackling issues that affect individuals globally I feel that they have a responsibility to ensure that their learnings reach the largest audience possible - allowing for that audience to read, reuse or build upon these learnings to their betterment. I see very little in the current framework of academia that permits freedom - the publish or perish environment quells the freedom of many practices. In order to gain tenure or recognition as an expert in your chosen field you must publish in certain venues, speak at certain conferences, and gain funding from specific sources. Plan S is aimed at restructuring an ecosystem that already restricts freedoms on access and reuse of information. It's about fostering a community within knowledge dissemination - one that is not solely controlled or focused on those who are privileged enough to play. Plan S cannot solve all of the issues tangled within the topic of scholarly dissemination and careers in academia, but it is generating discussion globally. However, I urge people to refrain from viewing the principles as restrictive measures and instead think about the potential - a corpus of knowledge openly available to anyone, anywhere, with reuse rights, the ability to mine, create translations, and participate in research discourse globally regardless of financial background. A right to publish does not equate to the right to paywall or constrict who can access, read or reuse knowledge."

Both perspectives hit on very real issues in academia, the need to restructure the existing scholarship system and to invest in the resources faculty need most right now. Academic freedom is bandied about regarding this topic as though it is some sort of force shield for the status quo. There is meaningful work to be done to change priorities in higher education and the better effort is to find ways to improve upon the systems currently in place.

The power held by the funding bodies is that they help to drive part of this change through their monetary support. In the United States, the funding patterns by state and federal support is one of diminishing returns. The main investors in higher education are those most directly benefiting from it, the students. For their investments, students deserve to have access to the scholarship they are supporting. It's time to talk about their academic freedom to have work they participate in and support be made freely available to them. Ultimately, what exactly do faculty lose by supporting an OA mandate or Plan S? As Janis Joplin sang: "Nothing don't mean nothing if it ain't free."

\section{Author's References}

1. European Commission, 'Plan S' and 'cOAlition S' - Accelerating the transition to full and immediate Open Access to scientific publications, 2018, <https://ec.europa.eu/commission/commissioners/2014-2019/moedas/announcements/ plan-s-and-coalition-s-accelerating-transition-full-and-immediate-open-access-scientific_en>

2. Wellcome Trust, Open access policy 2020, 2018, <https://wellcome.ac.uk/sites/default/files/wellcome-open-access-policy-2020.pdf>

3. Wellcome Trust, Wellcome and the Bill \& Melinda Gates Foundation join the Open Access coalition, 2018, <https://wellcome. ac.uk/press-release/wellcome-and-bill-melinda-gates-foundation-join-open-access-coalition>

4. Science Europe, cOAlition S, 2018, <https://www.scienceeurope. org/coalition-s/>

5. Smith, MacKenzie and Ventry, Jr., Dennis J., Potential Changes to UC's Relationship with Elsevier in January 2019, 2018, <https:// www.library.ucdavis.edu/news/potential-changes-to-ucs-relationship-with-elsevier-in-january-2019/>

6. American Association of University Professors, 1940, 1940 Statement of Principles on Academic Freedom and Tenure, <https:// www.aaup.org/report/1940-statement-principles-academic-freedom-and-tenure>

7. Nelson, Cary, 2010, “Defining Academic Freedom.” Inside Higher Education, <https://www.insidehighered.com/views/2010/12/21/ defining-academic-freedom>

8. Joplin, Janis, $1970 \mathrm{Me}$ and Bobby McGee (Lyrics), <https://youtu. be/CQ-QfMv7Fzw> 